\title{
Iron in haemoglobinopathies and rare anaemias
}

\section{John Porter}

\section{Thalassaemia and Sickle Cell Unit, Haematology Department, University College, London, UK}

\begin{abstract}
Iron overload in haemoglobinopathies and rare anaemias may develop from increased iron absorption secondary to hepcidin suppression, and/or from repeated blood transfusions. While the accumulation of body iron load from blood transfusion is inevitable and predictable from the variable rates of transfusion in the different conditions, there are some important differences in the distribution of iron overload and its consequences between these. Transfusion-dependent thalassaemia (TDT) is the best described condition in which transfusional overload occurs. Initially iron loads into macrophages, subsquently hepatocytes, and then the endocrine system including the anterior pituiatry and finally the myocardium. The propensity to extrahepatic iron spread increases with rapid transfusion and with inadequate chelation therapy but there is considerable interpatient and interpopulation variability in this tendency. The conduits though which iron is delivered to tissues is through non transferrin iron species (NTBI) which are taken into liver, endocrine tissues and myocardium through L-type calcium channells and possibly through other channells. Recent work by the MSCIO group ${ }^{1}$ suggests that levels of NTBI are determined by three mechanisms: i) increasing with iron overload; ii) increasing with ineffective erythropoieis; iii) and decreasing when level of transferrin iron utilisation is high. In TDT all three mechanisms increase NTBI levels because transferrin iron utilisation is suppressed by hypertransfusion. It is hypothesized that the transfusion regimen and target mean $\mathrm{Hb}$ may have a key impact on NTBI levels because high transfusion
\end{abstract}

regimes may suppress the 'sink' effect of the erythron though decreased clearance of transferrin iron. In sickle cell disease (SCD) without blood transfusion the anaemia results mainly from haemolysis rather than from ineffective erythropoiesis. ${ }^{2}$ Thus there is a tendency to iron depletion because of urinary iron loss from intrascular haemolysis outweighs any increased iron absortion from hepcidin suppression. These effects result in a low trasferrin saturation and NTBI levels and a low tendency from extrahepatic iron distribution. In rare anaemias that result from low production of red cells such as Diamond Blackfan Anaemia (DBA) there is little or no clearance of transferrin iron by the erythron. This leads to high NTBI and a high tendency to extrahepatic iron distribution in DBA. These differences potentially impact on strategies for monitoring and treatment of iron overload in these different conditions.

\section{References}

1. Porter JB, Walter PB, Neumayr LD, et al. Mechanisms of plasma non-transferrin bound iron generation: insights from comparing transfused diamond blackfan anaemia with sickle cell and thalassaemia patients. Br J Haematol 2014;167:692-6.

2. Porter JB, Garbowski M. Consequences and management of iron overload in sickle cell disease. Hematology Am Soc Hematol Educ Program 2013;2013:447-56.

\author{
Correspondence: John Porter, Thalassaemia and Sickle Cell Unit, \\ Haematology Department, University College, London, UK \\ E-mail: j.porter@ucl.ac.uk \\ Key words: iron; haemoglobinopathies; rare anaemias; blood transfusions; \\ thalassaemia. \\ (C) Copyright J. Porter, 2014 \\ Licensee PAGEPress, Italy \\ Thalassemia Reports 2014; 4:4859 \\ doi:10.4081/thal.2014.4859 \\ This article is distributed under the terms of the Creative Commons \\ Attribution Noncommercial License (by-nc 3.0) which permits any noncom- \\ mercial use, distribution, and reproduction in any medium, provided the orig- \\ inal author(s) and source are credited.
}

